\title{
Structural Development for Well Service Activity in Limited Capacity Platform
}

\author{
Marciela Esa Dewa ${ }^{1, *}$, Muhammad Arifin ${ }^{1}$, and Eki Primudi ${ }^{1}$ \\ ${ }^{1}$ Facility Engineering \& Integrity (FEI), PT PHE West Madura Offshore (WMO), Jakarta 12520, Indonesia
}

\begin{abstract}
The idea is to replace drilling rig, which is utilized for work over/well services activities, with working barge. The challenge comes from the operation and structural platform capacity since the majority of PHE WMO wellhead platform has limited capacity issue and braced monopod type. To minimize the risk of drilling equipment placed on the platform, engineering study is proposed to ensure the reliability of the platform. The process and method of operation during well service activity will also be developed. The proposed mitigation includes: Global Structural Check for Platform Integrity, Local Structural Check for Strengthening, Localized load for Additional Equipment, and Weather-Time-Frame Constraint. Using the proposed methods, PHE WMO can ensure the platform integrity and ensure SAFETY during well service activities.
\end{abstract}

\section{Introduction}

Pertamina PHE WMO as a Cooperation Contract Sharing (K3S) of SKK MIGAS operates in the West Madura Offshore block. Currently WMO operates 8 well-head platforms, and most of these platforms are brace monopod platforms. This type of platform has some advantages, especially from the installation side. However it has redundancy of only one main support. Well services activity, which has been programmed periodically, is required to maintain the well integrity and production demand. Drilling rig has been much preferred to be utilized since the minimum impact to the platform, as the equipment are mostly placed on the rig itself.

Current oil industry situation demands efficiency. The use of Drilling Rig needs to be reviewed and the idea to replace it with Working Barge is proposed.

Replacing drilling Rig with working Barge will save the operational activities of well service thus saving operation cost. However, the safety and security of workers and facilities shall still be addressed. The equipment and the operation that was once placed on the Rig during well service must take place on the platform. As a result the platform capacity shall be revisited.

\section{Data and Method}

Working barge utilization for the well-service activity requires all related equipment to be placed on the platform. This is the main concern since the capacity of the platform is limited.

Several previous structural studies show the platform limitation, such as:
Table 1. WMO Structural Analysis Result

\begin{tabular}{|c|c|}
\hline Document \& Title & Remarks \\
\hline $\begin{array}{l}\text { PHEWMO-S-TEN-0012, } \\
\text { "Engineering Technical } \\
\text { Note - Plan of Additional } \\
\text { 30in conductors at KE-30" }\end{array}$ & $\begin{array}{l}\text { Executive Summary: } \\
\text { "it is not recommended } \\
\text { to add any additional } \\
\text { equipment loaded on } \\
\text { deck more than } 5.0 \\
\text { MT (due to pile safety } \\
\text { factor in storm } \\
\text { condition is } 1.5 \text { nearest } \\
\text { to the minimum } \\
\text { required as per API } \\
\text { RP2A)". }\end{array}$ \\
\hline $\begin{array}{l}\text { PHEWMO-PHE38A-S- } \\
\text { RPT- 0001 Rev.1, "In } \\
\text { Place Analysis Report for } \\
\text { PHE-38A Platform" }\end{array}$ & $\begin{array}{l}\text { Executive Summary: } \\
\text { "Based on in-place } \\
\text { analysis result, it is } \\
\text { found that the PHE- } \\
\text { 38A platform is non- } \\
\text { compliance to the } \\
\text { code. However, the } \\
\text { platform is still in } \\
\text { marginal integrity for } \\
\text { operation ..." }\end{array}$ \\
\hline
\end{tabular}

After identifying the condition and determining the objective, two solutions are then proposed:

- Well Service Method \& Operation

- Global and Localized Platform

This is also including barge positioning, in regards to the pipeline and weather constraint.

Corresponding author: marciela.dewa@gmail.com; marciela.dewa@pertamina.com 


\section{Result and Discussion}

\subsection{Well Service Method \& Operation}

The Well Service Method \& Operation relate with the necessary mitigation for well service activity. These include:

1. Well Service Equipment

2. Barge Type

3. Barge Positioning

Determining the well service equipment is needed to accommodate the platform limitation, both capacity and space. Criteria for the equipment shall be:

- Well Perform

- Lighter (than conventional equipment)

- $\quad$ Space efficient type

The proposed equipment is as follow,

Table 2. Proposed Well Service Equipment Weight and Properties

\begin{tabular}{|c|c|c|}
\hline Type & Footprint (Ft.) & $\begin{array}{c}\text { Weight } \\
\text { (tonne) }\end{array}$ \\
\hline $\begin{array}{c}\text { Slickline \& E- } \\
\text { Mast }\end{array}$ & $19,7 \times 1,5 \times 1,5$ & 4,5 \\
\hline $\begin{array}{c}\text { Coil Tubing } \\
\text { Jacking Frame }\end{array}$ & $10 \times 12 \times 16,25$ & 10 \\
\hline $\begin{array}{c}\text { Hydraulic } \\
\text { Workover Unit }\end{array}$ & $17 \times 12 \times 54$ & 20 \\
\hline
\end{tabular}

Barge type shall consider the necessary capacity carrying the well service equipment and safety of operation. Barge shall have minimum capacity of 3200tonne and clear deck space of 45 x $15 \mathrm{~m} 2$. Minimum 4 (four) points mooring are also necessary in accordance with PHE WMO marine regulation.

The barge positioning shall also consider wind prevailing direction, crane's platform, pipeline, and conductor location for safety operation. The proposed locations are as follow:

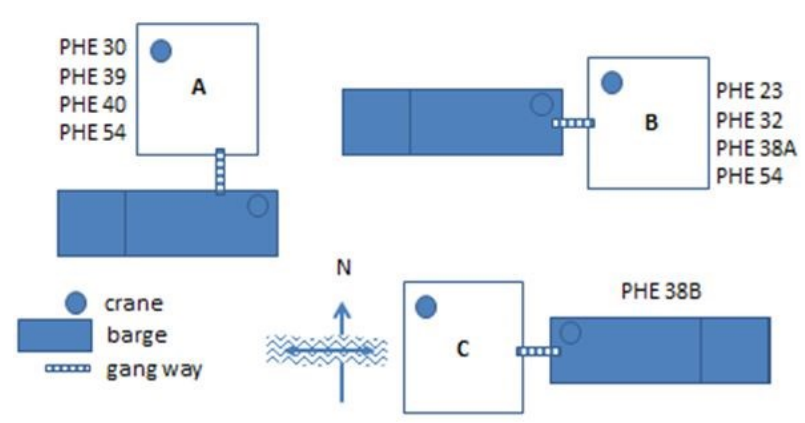

Figure 1. Barge Positioning Proposition

\subsection{Platform Capacity}

Platform capacity is based on structural analysis using standard industry code (API, AISC). It depends on many factors including: equipment load, environmental condition, material (member, pile) capacity (yield strength), etc.

The proposed assessment is outlined on the following chart,

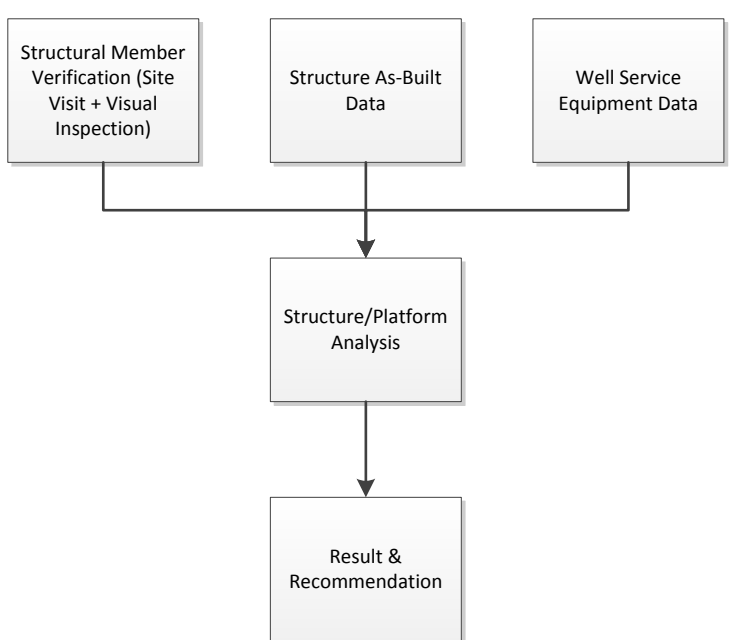

Figure 2. Flow Chart of Platform Analysis

Platform analysis using SACS software divided into two: (1) Global Platform Analysis and (2) Local Platform Analysis.

- Global platform analysis determines the overall platform capacity. Jacket and Pile capacity are the main indicators of this analysis.

- Local platform analysis provides structural capacity at specific locations. This analysis does not affect the integrity of the entire platform, but this damage still poses hazard/ safety risk. By knowing the local capacity of member, mitigation can be done to minimize the risk hazard. For example by strengthening the member or reduce the load on a particular part of the platform.

Structural analysis was performed for all active wellhead platform. However, this essay takes one example that represents the most, which is The Structural Review of PHE-38A Platform.

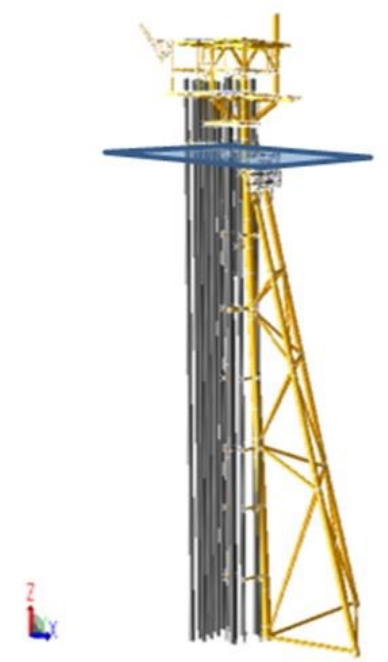

Figure 3. PHE-38A SACS Model 
PHE-38A platform has the most wells than any other wellhead platform. There is also a tilting issue $\left(1.08^{\circ}\right.$ based on 2014 measurement). PHE-38A platform details are as follow,

Table 3. PHE-38A Platform Specification

\begin{tabular}{|c|c|}
\hline Item & Remarks \\
\hline Water Depth & $+/-195 \mathrm{ft}$. \\
\hline Platform Type & $\begin{array}{l}\text { Braced Monopod (1 caisson with } \\
2 \text { batterpile) }\end{array}$ \\
\hline Jacket Diameter & $61^{\prime \prime}$ \\
\hline Pile Diameter & $56 "$ \\
\hline Jacket Elevation & $\begin{array}{l}\text { EL.(-) } 79^{\circ}-\text { Bracing } \\
\text { EL.(-) } 130^{\circ}-\text { Bracing } \\
\text { EL. (-) } 195^{\circ}-\text { Mudmat }\end{array}$ \\
\hline Topside Elevation & $\begin{array}{l}\text { EL. (+) 54' - Main Deck } \\
\text { EL. (+) } 42^{\prime}-\text { Mezzanine Deck } \\
\text { EL. (+) } 32^{\prime}-\text { Cellar Deck } \\
\text { EL. (+) 21'- Sub-Cellar Deck }\end{array}$ \\
\hline
\end{tabular}

The result of the structural analysis shows that some members have member check exceeding 1.00 (the ratio between the applied load versus maximum allowed load). Although the capacity has been exceeded, the structure is still operational. This is due to the contingency of loading and material.

To assure the structural capacity, several mitigations proposed:

- Directional Wave Analysis

- $\quad$ Localized Loading

- Time-Framing Environmental Condition

- Local Structural Strengthening

Wave load plays significant effect to the offshore structure. The current analysis uses the Omni Directional Wave/Current assumption. This is true for the new platform design despite conservative result, since it takes the maximum value of each load. Yet, for Brownfield development the Actual Directional Wave is used.

The result of the analysis using Directional Wave shows significant decrease in member check,
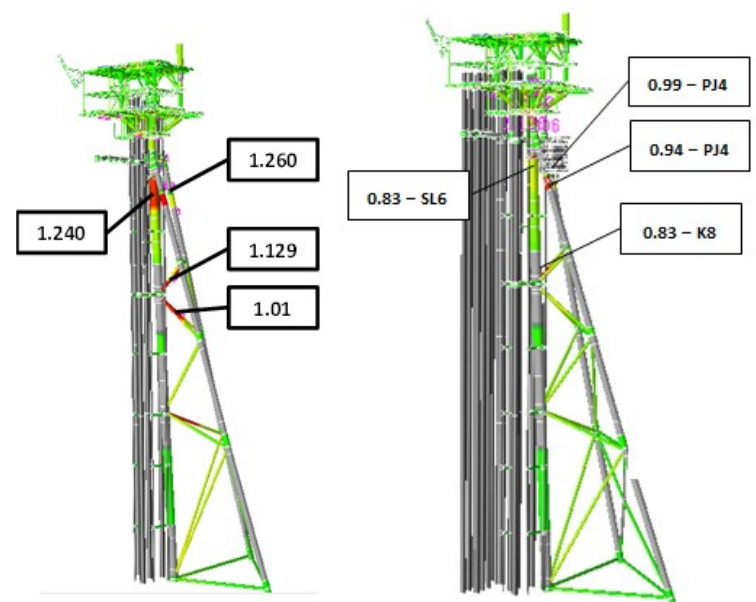

Figure 4. Analysis Result (Before - After Wave Directional)

Localized loading for well service equipment also need to be considered. This localized load assures the member integrity to avoid structural failure. Structural analysis is also performed to localize area, which is suitable for equipment laydown.

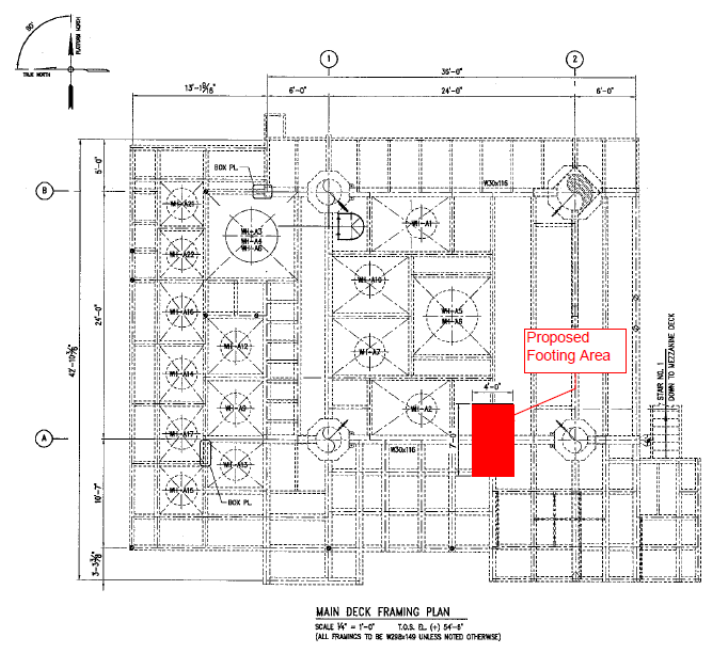

Figure 5. Localized Well Service Equipment Placement

Time-Framing Environmental Condition is based on the result of structural analysis. Offshore analysis considers two conditions, which are normal-operating and storm environmental conditions.

The result of structural analysis shows that the platform is able to accept loads with wave conditions below 2.5 meters (or non-monsoon conditions). This condition limits well service operation for monsoon condition, since the structural failure risk is greater (in addition to the barge mooring condition).

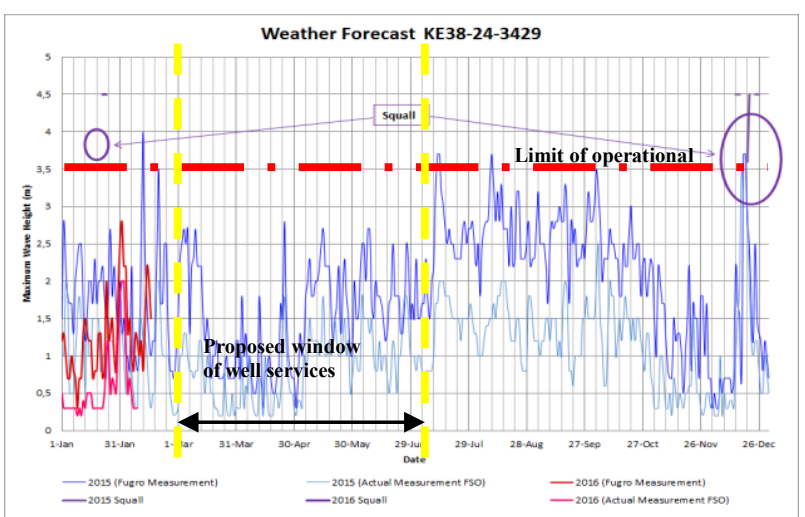

Figure 6. Time-Framing for Well Service Activity

Local Structural Strengthening is the least mitigation for local structural failure. Proposed strengthening is adding temporary columns or support during well service operation. Additional support will distribute excessive well service load to the main members. 


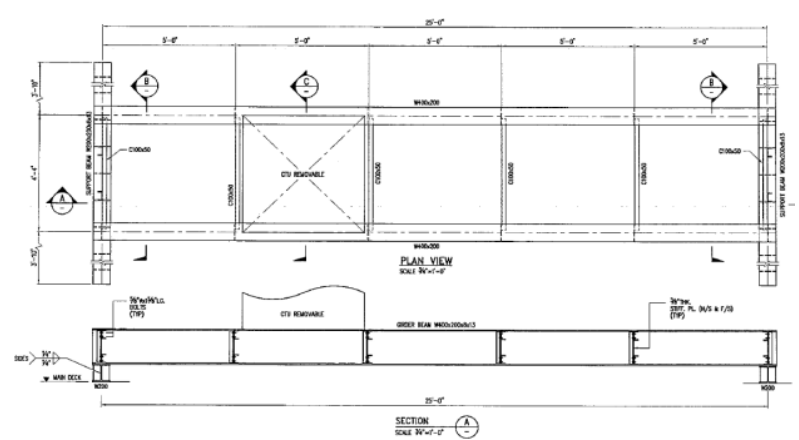

Figure 7. Local Structural Strengthening Supports

\section{Conclusion}

It can be concluded that the barge utilization within platform structural limitation is applicable for Well Service Operation under several conditions. These conditions including engineering assessment and operation method shall be followed to minimize the risk of well service activity to the platform and ensure safety of operation. This mitigation shall be supported with the reliability of inspection to assure mitigation and control.

Implementation of working barge utilization is expected to be executed in early 2018. The cost efficiency is expected to be achieved with the rental cost of working barge is lower than drilling rig.

\section{References}

1. API RP 2A-WSD, Recommended Practice for Planning, Designing and Constructing Fixed Offshore Platform - Working Stress Design, 21st edition. (Dec 2000)

2. API RP 2A-WSD, Errata and Supplement 3, (October 2007)

3. Facility Engineering \& Integrity PHE WMO, PHEWMO-FEI-S-TEN-0002: Engineering Technical Notes, Wellhead Platform Capacity due to Work Over/Well Service Activity, (2016)

4. Project Department PHE WMO, PHEWMO-STEN-0012: Engineering Technical Notes, Plan of Additional 30in conductors at KE-30, (2015)

5. Facility Engineering \& Integrity PHE WMO, PHEWMO-PHE38A-S-RPT- 0001 Rev.1: In Place Analysis Report for PHE-38A Platform, (2014) 